\title{
Long-Distance Pipe Jacking in Complex Urban Geological Environment
}

\author{
Yi Gong*, Yang Liu, Qigao Li \\ China First Metallurgical Group Co., Ltd., China \\ *Corresponding author: Yi Gong, 278974045@qq.com
}

Copyright: ( $) 2022$ Author(s). This is an open-access article distributed under the terms of the Creative Commons Attribution License (CC BY 4.0), permitting distribution and reproduction in any medium, provided the original work is cited.

\begin{abstract}
A steel underground pipeline with a diameter of $2.4 \mathrm{~m}$ and a total length of 3,617 $\mathrm{m}$ (plate thickness of $26 \mathrm{~mm}$ ) has been constructed in a city in central Hubei, and the engineering, procurement, and construction (EPC) project has been lifted from the upstream channel to supplement water to the downstream lake inside the city. Through preliminary geological survey data, site topographic and geomorphic survey, urban construction, as well as the requirements of the construction party, the preliminary arrangement of working wells and receiving wells as well as the selection and customization of pipe jacking machines have been proposed. Frequency conversion motor and remote monitoring technology are adopted for geotechnical change and long-distance pipe jacking. Through detailed survey, the rock and soil change section as well as gradual change conditions have been determined, the accuracy of construction mechanics calculation and construction operation control have improved, the basis and analysis basis are provided, and some experiences in construction operation are summarized.
\end{abstract}

Keywords: Long-distance pipe jacking; Complex geology; Urban area; New technology

Online publication: January 12, 2022

\section{Introduction}

With the development of the city, regional expansion, and population concentration, the pollution of the water system in the city is increasing, but its self-purification function is decreasing. In addition to rain and sewage diversion as well as sewage collection and treatment, a number of treatment projects have been built to open up circulating roads to replenish water for lakes in the city ${ }^{[1]}$. Powerful equipment manufacturing, frequency conversion technology application, remote monitoring, and reasonable technical schemes have promoted the smooth implementation of project construction ${ }^{[2]}$.

\section{Engineering-geological condition}

The pipeline enters downtown from the suburbs through villages, farmland, fish ponds, and Wuhan-Jiujiang Railway. The suburbs are alluvial-lacustrine plains, residual hills, and downlands, with large topographic fluctuations. Downtown areas are mainly urban trunk roads, enterprises, and institutions. The geological survey data is shown in Table 1. 
Table 1. Geological survey data

\begin{tabular}{|c|c|c|}
\hline Pile sections & Brief introduction of the geological layer & Geological stability judgment \\
\hline $\mathrm{K} 0+000 \sim \mathrm{K} 0+580$ & Silty clay layer and residual soil layer & Small difference and uniform foundation \\
\hline $\mathrm{K} 0+580 \sim \mathrm{K} 0+820$ & Mucky soil and silty clay & Large difference and uneven foundation \\
\hline $\mathrm{K} 0+820 \sim \mathrm{K} 2+870$ & $\begin{array}{l}\text { Moderately weathered (locally, highly weathered) } \\
\text { silty mudstone mixed with siltstone }\end{array}$ & Relatively stable and uniform foundation \\
\hline $\mathrm{K} 2+870 \sim \mathrm{K} 3+450$ & $\begin{array}{l}\text { Silty clay layer, moderately weathered silty mudstone } \\
\text { mixed with siltstone }\end{array}$ & Large difference and uneven foundation \\
\hline $\mathrm{K} 3+450 \sim \mathrm{K} 3+898$ & Silty clay layer & Small difference and uniform foundation \\
\hline
\end{tabular}

\section{Division of pipe jacking sections and selection of pipe jacking machines}

According to the geological survey data, site topographic and geomorphic survey, urban construction, and the requirements of the construction party, the division of pipe jacking section is proposed as shown in Table 2.

Table 2. Proposed division of pipe jacking sections

\begin{tabular}{cccccc}
\hline Section pile number & $\begin{array}{c}\text { Length } \\
\text { (m) }\end{array}$ & Jacking direction & Flow slope & \multicolumn{2}{c}{ Center elevation of pipe jacking (m) } \\
\cline { 5 - 6 } & & & Working well & Receiving well \\
\hline 1\#K0+265 - 2\#K0+500 & 235 & 2\# to 1\# & $4.29 \%$ & 12.00 & 13.01 \\
2\#K0+500 - 3\#K1+020 & 520 & 2\# to 3\# & $-0.44 \%$ & 12.00 & 12.23 \\
3\#K1+020 - 4\#K1+360 & 340 & 4\# to 3\# & $-0.44 \%$ & 12.38 & 12.23 \\
4\#K1+360 - 5\#K1+880 & 520 & 4\# to 5\# & $-0.57 \%$ & 12.38 & 12.68 \\
5\#K1+880 - 6\#K2+448 & 568 & 6\# to 5\# & $-0.57 \%$ & 13.00 & 12.68 \\
6\#K2+448 - 7\#K2+988 & 540 & Turn to the ground & Cross Railway & & \\
7\#K2+988 - 8\#K3+900 & 912 & 8\# to 7\# & $0.274 \%$ & 10.00 & 12.50 \\
\hline
\end{tabular}

From the detailed study of geological prospecting data, it can be appreciated that there is no problem in the geology of the project site as the pipeline foundation. However, at present, there are mainly hob types and reamer types for pipe jacking machines. Hob type is conducive to cutting rock geology, while the reamer type is conducive to cutting sand geology. From the description in Table 1, it can be seen that the pile sections of $\mathrm{K} 0+000 \sim \mathrm{K} 0+580, \mathrm{~K} 0+580 \sim \mathrm{K} 0+820$, and $\mathrm{K} 3+450 \sim \mathrm{K} 3+898$ have muddy soil, silty clay, and residual soil layer, but they are more suitable for reamer type pipe jacking machine; K0+820 K2+870 is moderately weathered (locally, highly weathered) silty mudstone mixed with siltstone, which is more suitable for hob type pipe jacking machine; $\mathrm{K} 2+870 \sim \mathrm{K} 3+450$ is a silty clay layer and moderately weathered silty mudstone mixed with siltstone. The reamer type pipe jacking machine is not suitable for cutting rock while the hob type pipe jacking machine is not suitable for cutting soil layer ${ }^{[3]}$.

Table 2 is the construction deployment formulated according to the site topographic and geomorphic survey, urban construction, as well as the requirements of the construction party ${ }^{[4]}$. However, it has failed to avoid the problem of a suitable model of pipe jacking machine. For example, 2\#k0+500 - 3\#k1+020 and $7 \# \mathrm{k} 2+988-8 \# \mathrm{k} 3+900$ are rock soil mixed sections. With the help of the equipment manufacturer, the hob type and reamer type are combined to better solve the cutting problem of the mixing section suitable for both, rock and soil. At the same time, it is equipped with variable frequency motor drive to change the influence on rock and soil jacking force with different hardness and long-distance power supply voltage drop; in addition, it adds a pressure water gun to decompose the bonded soil in the slurry silo ${ }^{[5]}$. 


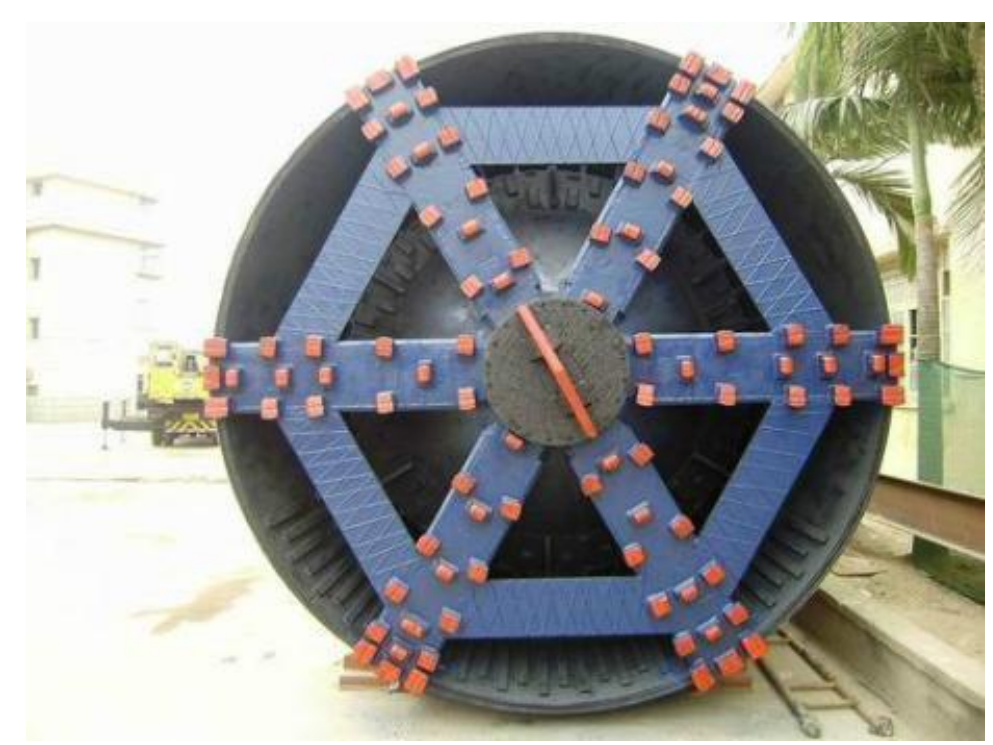

Figure 1. The pipe jacking nose that is suitable for soil reamer type

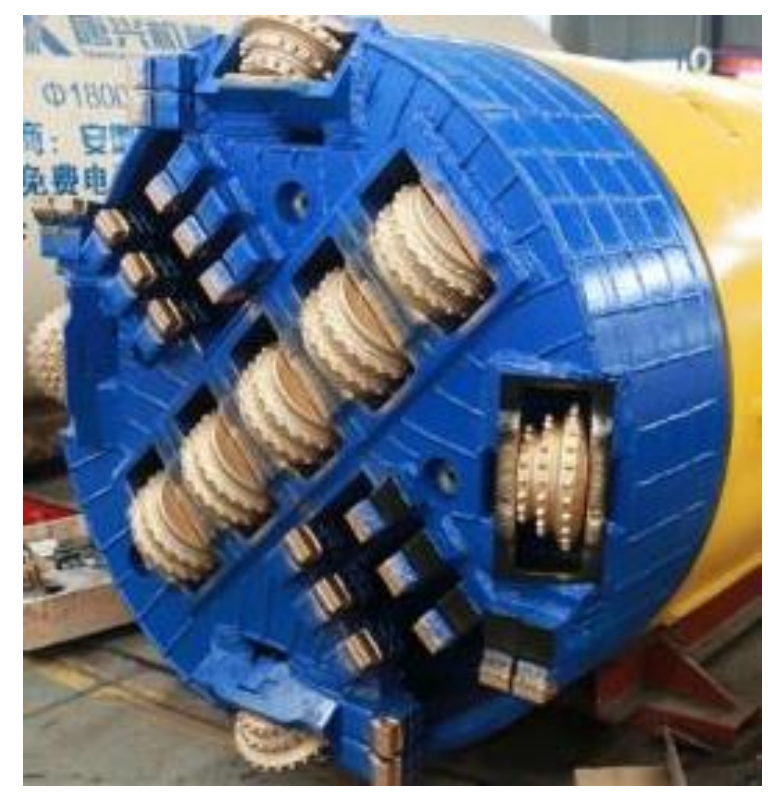

Figure 2. The pipe jacking nose that is suitable for soil and rock mixed section

\section{Purpose of supplementary survey and the supplementary survey points}

The boundary point or gradual length of silty clay and muddy clay or of silty clay and moderately weathered and highly weathered rock cannot be accurately found at the $30-50 \mathrm{~m}$ of the pipe jacking section, which can further verify the reflection of the preliminary survey data. The data obtained from supplementary survey can further correct the friction during jacking and then quickly and accurately analyze as well as determine the problems in case of abnormalities in the soil joint section ${ }^{[6]}$. According to construction records, technical measures such as deviation correction, frequency conversion deceleration, slurry concentration, grouting pressure, and grouting volume can be taken in advance for different geological transition sections ${ }^{[7]}$, So as to prevent land heave or settlement with the correct attitude of controlling jacking. At the same time, the purpose of on-site inspection is enhanced. The selection of supplementary survey points is to check the elevation and geological stratification of the previous survey profile, select the data of adjacent survey points, and use the insertion method to find approximate dividing points and transition points for positioning ${ }^{[8]}$. 


\section{Application of new technologies: programmable logic controller (PLC) and videos, variable frequency motor, and intermediate jacking station}

PLC integrates the pipe jacking operation on the operation cabinet (table) through electrical components, compiles it according to the operation flow, and then carries out manual intervention to realize automatic control. Without video monitoring, the PLC control cabinet must follow the pipe jacking progress (Figure 3). The operators are on duty in the PLC control cabinet. In long-distance pipe jacking construction, the operators and PLC control cabinet occupy the operation space and are not suitable for the long working environment of the personnel ${ }^{[9]}$. Therefore, with the application of high-definition (HD) camera, the operator and PLC control cabinet can be placed outside the working well, and the operator can operate remotely through video monitoring.

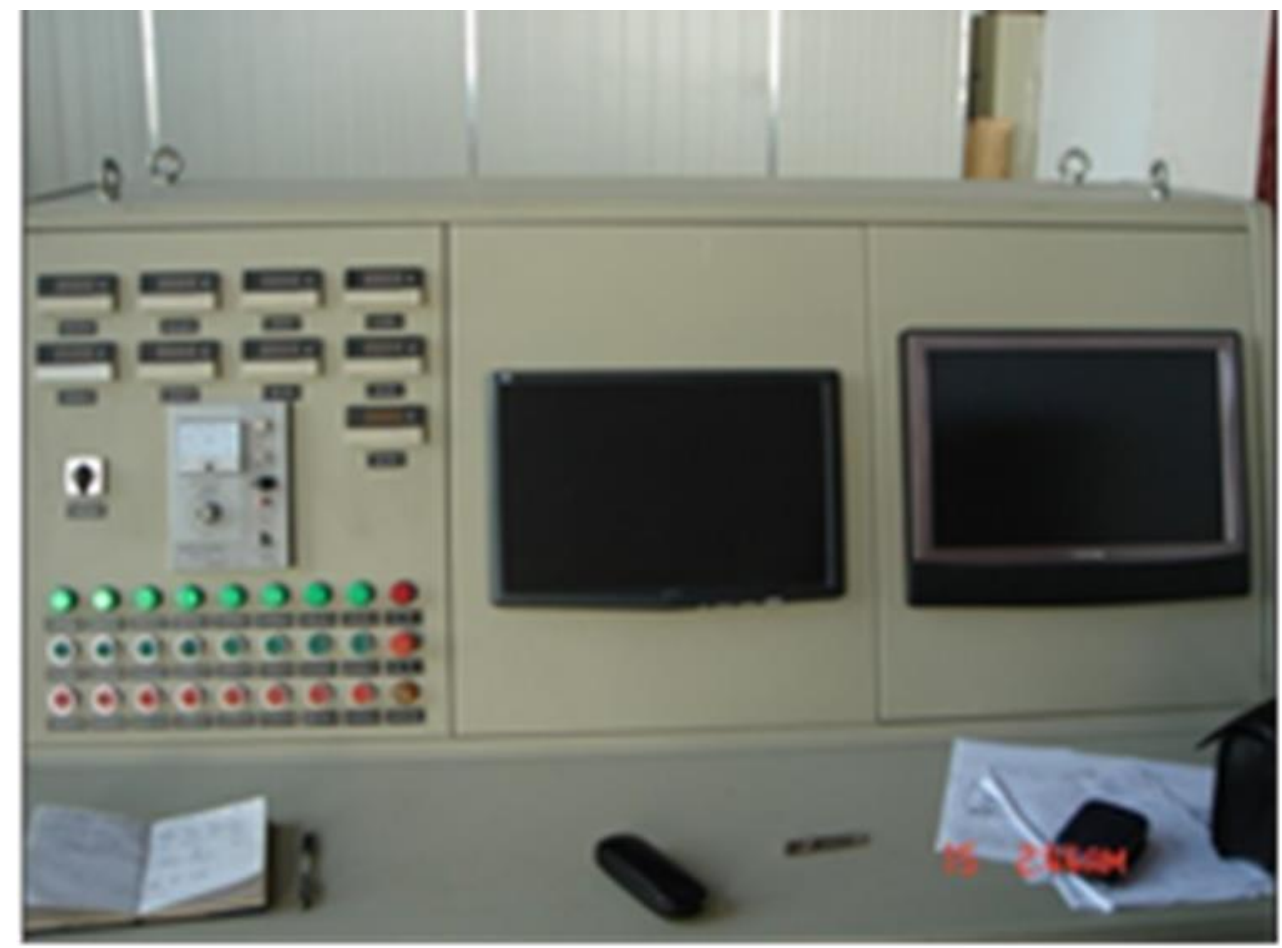

Figure 3. PLC control cabinet

In the intelligent era, the PLC control cabinet can also add air quality, humidity, and temperature sensing elements to detect the environment, set up safety chains, and start the ventilation equipment in time. Video monitoring is generally set at the working well, nose, mud pit, slag outlet, intermediate jacking station, etc. The operator can judge whether to intervene or not by the data displayed on the control cabinet, video monitoring images, and construction experience: the working status of the jack, the head, the slurry reserve and concentration, the rock and soil status of the slag discharge mouth, as well as the blockage of the pipeline ${ }^{[10]}$.

The application of variable frequency motor can adjust the transmission frequency according to the soil plasticity and rock hardness, so as to obtain more suitable cutting force and jacking speed as well as to protect the jacking pipe and node blade. At the same time, the voltage drop is obvious for long-distance construction lines. The damage to the nose motor can be avoided by starting at a low frequency and through frequency modulation. In the soil and rock transition section, the cutting force and jacking speed are controlled by frequency conversion, which has a good effect on maintaining the normal attitude of the nose. In the rock section, the cutting force and jacking speed are controlled by frequency conversion to adjust the relaxation between the blade and the rock to make the cutting smoother ${ }^{[11]}$. 
For long-distance pipe jacking, the jacking force will gradually decrease due to the friction of rock and soil. At this time, it will appear in the allowable pressure bearing range of pipeline materials, and it will not move forward due to insufficient jacking force. If the initial jacking force increases, the cement pipe would be crushed and the steel pipe would be transversely deformed. The intermediate jacking station technology is used to solve this problem. In brief, the intermediate jacking station is to make a steel tube support suitable for the diameter of the designed tube and install a group of small stroke hydraulic jacks on the tube support. In the construction preparation stage, the intermediate jacking station is installed in the middle of the jacking pipe according to the calculated spacing to transfer the relay, thus offsetting the friction loss ${ }^{[12]}$. During construction, the working well, nose, mud pit, slag discharge port, and intermediate jacking station can be monitored by video and the data at the PLC control cabinet according to the calculation guidance; hence, the installation position of intermediate jacking station can be properly adjusted.

When the total thrust reaches $40 \%$ to $60 \%$ of the total thrust of the intermediate jacking station, the first intermediate jacking station shall be placed. When $70 \%$ to $80 \%$ of the total thrust of the intermediate jacking station has been reached, one intermediate jacking station shall be placed. When the main jacking cylinder reaches $90 \%$ of the total thrust of the intermediate jacking ring, the intermediate jacking ring must be enabled.

\section{Conclusion}

In a complex geological environment, long-distance pipe jacking construction requires many complex construction technologies. In today's era, the rapid development of science as well as the research and application of advanced technologies have greatly assisted the progress of construction technology. This paper provides a simple summary of the application of new technologies in addition to construction experiences in hope to provide a reference although many main and key technologies have not been included in this paper.

\section{Disclosure statement}

The authors declare that there is no conflict of interest.

\section{References}

[1] Cui H, 2021, Comprehensive Research on Long Pipe Diameter Distance Pipe Jacking Engineering under Complex Geological Conditions. China Metal Bulletin, 2021(12): 2.

[2] Zhang J, 2020, Research on Jacking Force Control of Long Distance and Large Diameter Pipe Jacking Tunnel under Complex Geological Conditions. China Construction, 2020(14): 3.

[3] Wang Q, Wang Y, 2020, Discussion and Practice of Pipe Jacking Technology in Long Distance and Large Diameter Complex Geology in Mountainous Area. Shanxi Architecture, 46(2): 2.

[4] Cheng Q, 2020, Study on Construction Efficiency and Influencing Factors of Pipe Jacking under Complex Geological Conditions. Intelligent City, 6(3): 2.

[5] Sun X, 2020, Study on Construction Efficiency and Influencing Factors of Pipe Jacking under Complex Geological Conditions. DOI: 10.12159/j.issn.2095-6630.2020.11.1570

[6] Guo J, Zhu T, 2021, Application of Open-Cut Pipe Jacking in Pipeline Construction of Complex Geological Section. Science \& Technology Information, 2021(2020-30): 65-67.

[7] Song H, Jia X, Zhang P, et al., 2020, Discussion on Pipe Jacking Technology under Complicated Geological Condition of Large Diameter Pebble. Modern Property Management, 2020(7): 2. 
[8] He X, 2020, Construction and Settlement Control of Municipal Road Sewage Pipe Jacking under Complex Geological Conditions. DOI: 10.12159/j.issn.2095-6630.2020.16.2722

[9] Hu F, 2020, Research and Application of Long-distance Pipe Jacking Technology in Municipal Water Supply and Drainage Construction. Zhejiang University of Technology.

[10] Jin D, Chen Y, 2020, Discussion on Pipe Jacking Construction of Municipal Sewage Pipeline Engineering. Ecological Environment and Protection, 3(7): 61-62.

[11] Li Y, Cheng H, Cao G, et al., 2020, Application of Non-blasting Rock Excavation Technology in Hard Rock Stratum During Pipe Jacking. Water Resources and Hydropower Engineering, 51(6): 9.

[12] Gu M, Yao X, Huang S, 2020, Construction Method of Finished Sewage Pipe Network under Complex Geological Conditions. SooPAT, 2020: CN110700378A.

Publisher's note

Bio-Byword Scientific Publishing remains neutral with regard to jurisdictional claims in published maps and institutional affiliations. 